\title{
Targeted next generation sequencing and family survey enable correct genetic diagnosis in CRX associated macular dystrophy - a case report
}

\author{
Saoud Al-Khuzaei ${ }^{1,2 \dagger}$, Karl A. Z. Hudspith ${ }^{1 \dagger}$, Suzanne Broadgate ${ }^{1}$, Morag E. Shanks ${ }^{3}$, Penny Clouston ${ }^{3}$, \\ Andrea H. Németh ${ }^{1,4}$, Stephanie Halford ${ }^{1}$ and Susan M. Downes ${ }^{1,2^{*}}$ (i)
}

\begin{abstract}
Background: We present 3 members of a family with macular dystrophy, originally diagnosed as Stargardt disease, with a significantly variable age at onset, caused by a heterozygous mutation in CRX.

Case presentation: A 43-year-old female with bull's eye maculopathy, whose sister was diagnosed with Stargardt disease previously at another centre, was found to have a single $A B C A 4$ variant. Further examination of the family revealed that the asymptomatic father was also affected, indicating a dominant pattern of inheritance. In addition, the $A B C A 4$ variant was not identified in the sister originally diagnosed with Stargardt disease. Next generation sequencing identified a heterozygous c.121C > T, p.R41W missense mutation in CRX in all 3 affected members.

Conclusions: We describe a common phenotype, but with variable age at onset, with autosomal dominant inheritance and reduced penetrance in a family found to have a pathogenic sequence variant in CRX. This illustrates the importance of panel based molecular genetic testing accompanied by family studies to establish a definitive diagnosis.
\end{abstract}

Keywords: Retina, Macular dystrophy, Next generation sequencing, CRX, ABCA4 sequence variant, mutation, Phenotype/genotype, reduced penetrance, family survey

\section{Background}

Macular dystrophies (MD) may have certain recognisable clinical features that can pinpoint a specific diagnosis enabling a secure phenotype classification. However, in some cases patients present with retinal features that are shared by different conditions, known as phenocopies. In addition, since the advent of NGS, more than one potential causative gene variant may be identified in a family with an inherited retinal dystrophy thus making a definitive diagnosis difficult. However molecular genetic testing, accompanied by careful family studies with segregation of the variant with disease, can enable a conclusive diagnosis. This is important for prognosis, genetic counselling, and potential therapeutic interventions such as gene therapy.

\footnotetext{
* Correspondence: susan.downes@eye.ox.ac.uk

${ }^{\dagger}$ Saoud Al-Khuzaei and Karl A. Z. Hudspith joint first authors

${ }^{1}$ Nuffield Laboratory of Ophthalmology, Nuffield Department of Clinical Neurosciences, University of Oxford, Oxford, UK

${ }^{2}$ Oxford Eye Hospital, John Radcliffe Hospital, Headley Way, Oxford OX9 3DU, UK

Full list of author information is available at the end of the article
}

\section{Case presentation}

A 43-year-old white female (II:2) presented with reduced vision in her right eye, inadvertently noticed when closing her left eye. On examination visual acuities were 6/

(c) The Author(s). 2021 Open Access This article is licensed under a Creative Commons Attribution 4.0 International License, which permits use, sharing, adaptation, distribution and reproduction in any medium or format, as long as you give appropriate credit to the original author(s) and the source, provide a link to the Creative Commons licence, and indicate if changes were made. The images or other third party material in this article are included in the article's Creative Commons licence, unless indicated otherwise in a credit line to the material. If material is not included in the article's Creative Commons licence and your intended use is not permitted by statutory regulation or exceeds the permitted use, you will need to obtain permission directly from the copyright holder. To view a copy of this licence, visit http://creativecommons.org/licenses/by/4.0/ The Creative Commons Public Domain Dedication waiver (http://creativecommons.org/publicdomain/zero/1.0/) applies to the data made available in this article, unless otherwise stated in a credit line to the data. 

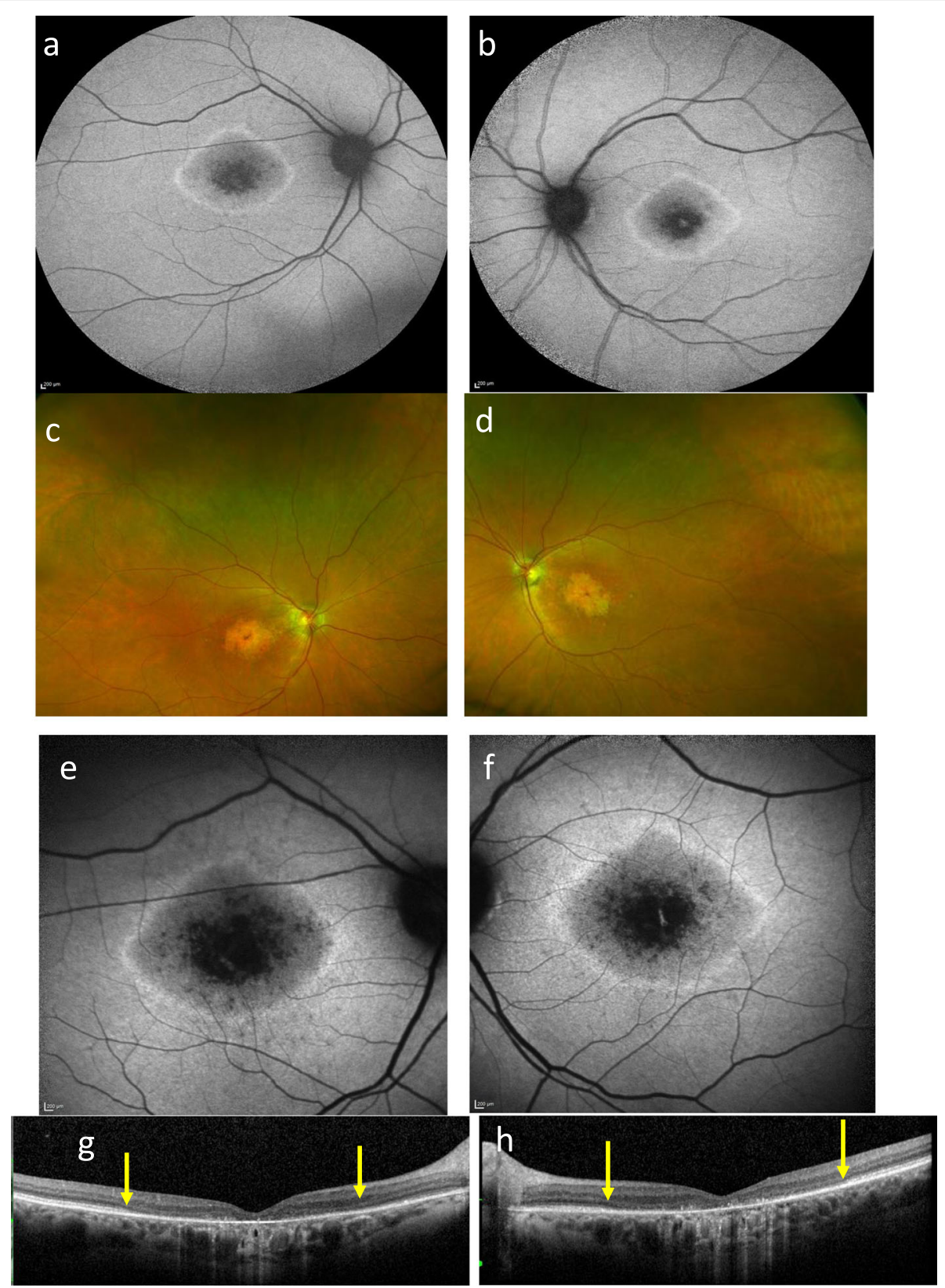

Fig. 1 Images of proband at different time points: a and $\mathbf{b}$ show AF at age of 51,8 years after first presentation with a central preserved spot of AF, surrounded by atrophy, and a ring of AF external to the atrophy. $\mathbf{c}$ and $\mathbf{d}$ show wide field Optos images at age of 59 (16years after presentation) with central atrophy; $\mathbf{e}$ and $\mathbf{f}$ show AF at the same time showing enlargement of the decreased AF signal; $\mathbf{g}$ and $\mathbf{h}$ OCT showing loss of the EZ between the yellow arrowskey: Autofluorescence AF, Optical coherence tomography (OCT), Ellipsoid Zone (EZ).

60 OD and 6/7.5 OS. Fundoscopy revealed bilateral central atrophy, seen clearly on autofluorescence imaging (AF) (Fig. 1a and b). Eight years later AF imaging showed a preserved small central spot of AF, surrounded by a reduced AF signal corresponding to the area of atrophy, which increased in size over time, with a ring of AF. (Fig. 1c-f). Optical coherence tomography (OCT) imaging, 10 years after initial presentation, showed loss of the ellipsoid zone (EZ) (Fig. 1g and h). These features were consistent with a macular dystrophy, with features of bull's eye maculopathy (BEM). Electrophysiology testing showed that the pattern electro-retinogram was significantly affected in both eyes; the rod electroretinogram (ERG) showed slight increase in implicit times of both 'a' and 'b' waves with significant reduction of the ' $b$ ' wave amplitude. The photopic and $30 \mathrm{~Hz}$ flicker stimuli were normal; the EOG light rise was borderline reduced in the right eye, and normal in the left 

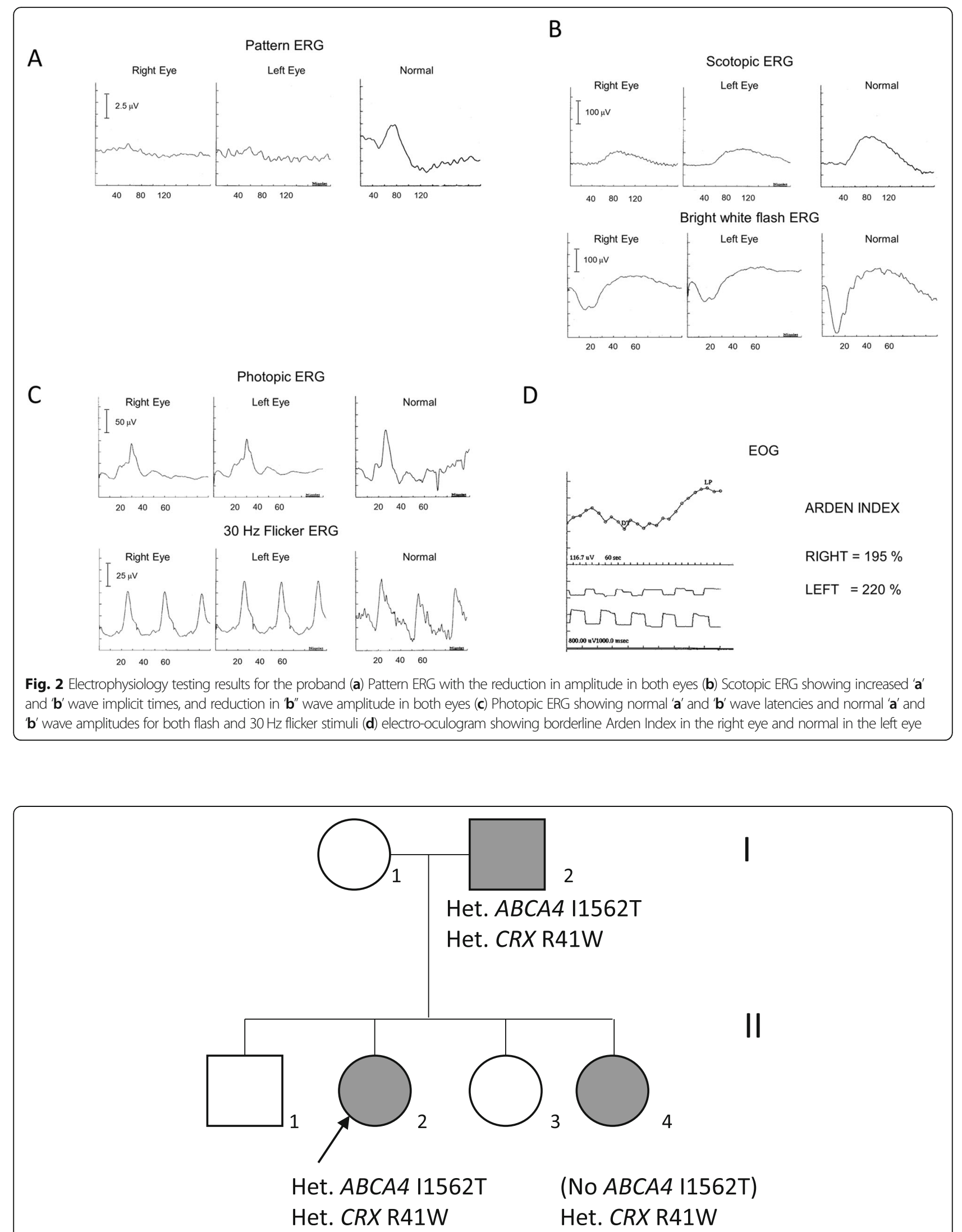

Fig. 3 a Pedigree of the family. The black arrow indicates the proband II:2. The shaded boxes and circles indicate affected individuals (b). 


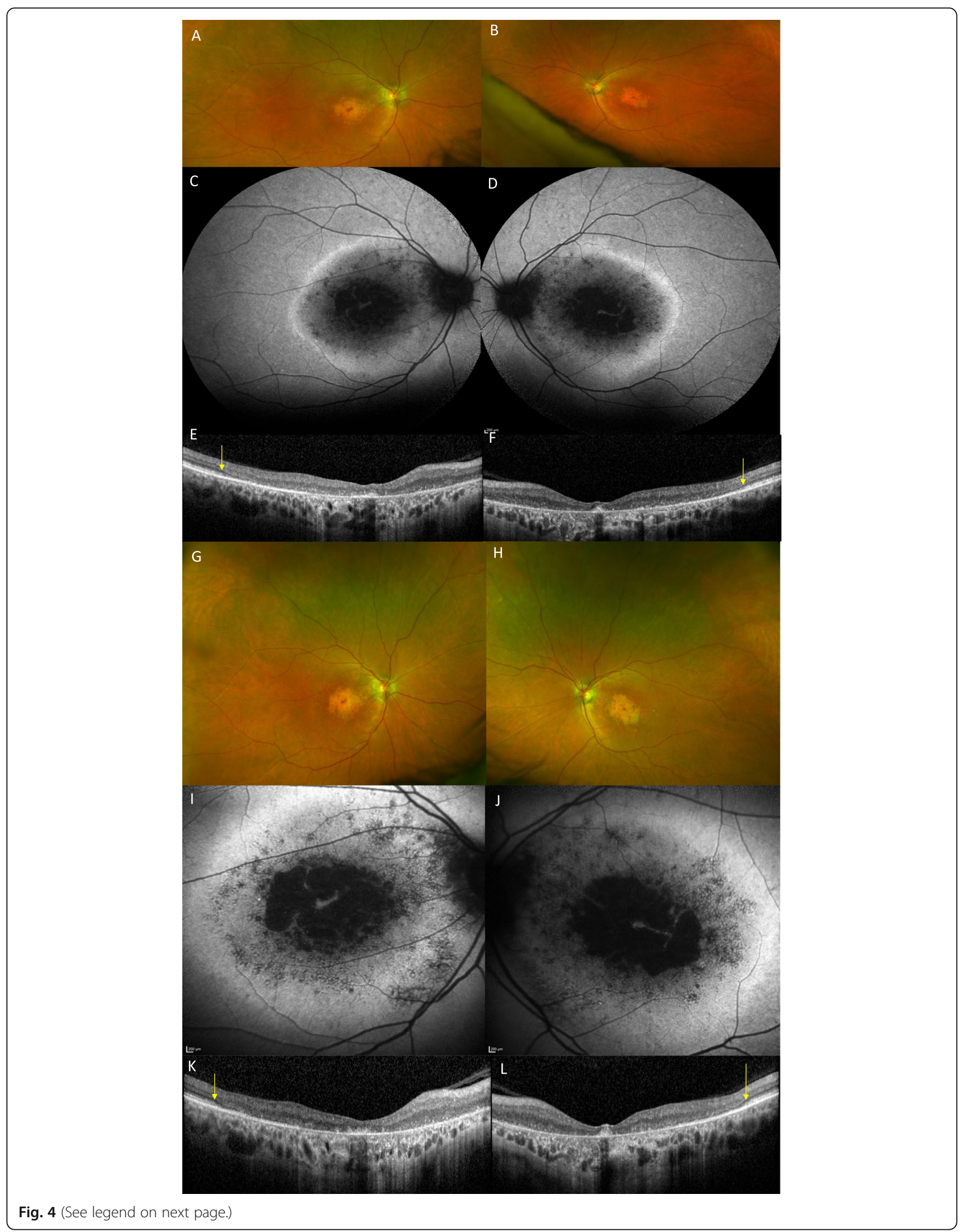


(See figure on previous page.)

Fig. 4 Imaging of the proband's younger sister (II/4). Images (a to $\mathbf{f}$ ) at review aged 56, at 38 years after diagnosis. Optos imaging showing atrophic maculae (a and $\mathbf{b}$ ). Autofluorescence (AF) shows loss of signal centrally corresponding to atrophy with a surrounding band of increased AF within the arcades (c and $\mathbf{d}$. optical coherence tomography (OCT) imaging showing the temporal extent of the loss of the ellipsoid zone demarcated by yellow arrows. e and $\mathbf{f}$. Images ( $\mathbf{g}$ to $\mathbf{l}$ ) showing increased atrophy after a 4-year interval. Optos imaging shows increased bilateral macular atrophy ( $\mathbf{g}$ and $\mathbf{h}$ ). AF imaging shows extension of patchy AF surrounding the central atrophy with a small preserved foveal remnant (i and $\mathbf{j})$. OCT showing further extension of the loss of the ellipsoid zone demarcated by the yellow arrows

(Fig. 2). In view of the family history of Stargardt macular dystrophy (STGD1) and the BEM phenotype genetic testing for $A B C A 4$ variants was undertaken. Sanger sequencing was used to screen all 50 exons and approximately 50 base pairs of flanking intronic regions (standard practice at the time) in the proband. This identified a single previously reported pathogenic variant c.4685 T > C, p.(I1562T) [1], in the proband (II/2, Fig. 3), but a second variant was not identified; (at that time, 15-30\% of STGD patients were reported as having only one detectable mutation in ABCA4 [2-4]). A family survey was then performed including her sister (II:4) and father (I:2), who were consented and examined. Her sister (II:4), previously diagnosed with STGD1 aged 18 years old, was re-examined at 46 years. Visual acuities were 6/60 right and left, and fundoscopy showed marked central atrophy (Fig. $4 \mathrm{a}$ and b). The atrophy seen on AF and OCT imaging were similar to that seen in the proband, but were more advanced (Fig. 4c to f). Multimodal imaging at follow up 4 years later, aged 54 years, showed a further increase in central atrophy (Fig. 4g-1). Their father (I:2), aged 70 years old, was asymptomatic with visual acuities of 6/6 right, and left with a normal appearing fundus (Fig. 5a and b). However, his AF imaging showed abnormalities of central stippled reduction in signal, consistent with early macular atrophy (Fig. $5 \mathrm{c}$ and $\mathrm{d}$ ), but less advanced than that seen in his daughters (Figs. 1 and 4). Nine years after his diagnosis, aged 79, his visual acuities had deteriorated to 6/60 right, and left and he had developed central atrophic changes similar to his daughters (Fig. 5e-j). Electrophysiology results were not available for II:4, or I:II. None of the family had any co-existing systemic disorders.

Segregation analysis in the family revealed that her father (I:2) carried the c.4685 $\mathrm{T}>\mathrm{C}$ variant, but the proband's affected sister (II:4) did not, indicating that this $A B C A 4$ variant was not relevant to the macular dystrophy in this family (Fig. 3).

Targeted sequencing of 70 genes associated with retinal degeneration was performed in the proband [5]. A heterozygous variant, c.121C > T (p.R41W), was identified in the cone-rod homeobox (CRX) gene. Sanger sequencing confirmed the variant was present in all three affected family members (Fig. 3). This variant has previously been reported as a dominant pathogenic variant that causes cone-rod dystrophy (CRD) [6]. The family were informed of the genetic diagnosis and had followup genetic counselling for an autosomal dominant disease inheritance pattern associated with variable expressivity and reduced penetrance.

\section{Discussion and conclusions}

Single $A B C A 4$ variants are frequently identified in patients phenotypically diagnosed with Stargardt macular dystrophy (STGD1) [2-4], $A B C A 4$ testing was undertaken because of the family history of STGD1 and because the siblings had a bull's eye macular dystrophy (BEM) appearance, which has been reported with $A B C A 4$ variants [7]. However once the family survey was performed, with no $A B C A 4$ variant identified in II/ 4 , and a macular dystrophy diagnosed in her asymptomatic father (I:2), an $A B C A 4$ retinopathy was excluded. The gene panel testing identified a pathogenic sequence variant in $C R X$. The $A B C A 4$ variant was designated to be an incidental finding (carrier status) (Fig. 3).

The CRX (cone rod homeobox) gene was first identified as an important regulator of photoreceptor cell development by Chen et al. in 1997 [8]. Then Swain et al. and Freund et al. reported that $C R X$ caused autosomal dominant cone rod dystrophy (CRD) $[6,9]$. Swain et al. first described the c.121 $\mathrm{T}>\mathrm{C}$ variant with a similar phenotype to that seen in the family we report here, except that their case in addition to rod degeneration also had cone dysfunction, which was not seen in the proband in our family [6]. A recent study by Nishiguchi et al. highlighted a range of phenotypes, observing that $C R X$ mutations occurring downstream in the homeobox domain (p.L299F, p.G243X, p.S204fs and p.S213fs) had diffuse or posteriorly extending bone-spicule pigmentation and vascular attenuation consistent with retinitis pigmentosa whilst all their other patients with mutations in the homeobox domain had a phenotype that was consistent with a macular dysfunction or CRD typified by a central region of decreased AF surrounded by a ring of increased AF and loss of the EZ in the maculae of all the symptomatic CRX patients [10]. In addition to variable expressivity, the Nishiguchi et al. study highlighted reduced penetrance; two of the families with the $C R X$ variant p.R41W had affected parents with a milder phenotype than their affected children. This is similar to the father I:2 in our family, who was asymptomatic when examined at the family survey. The visual acuity level in 


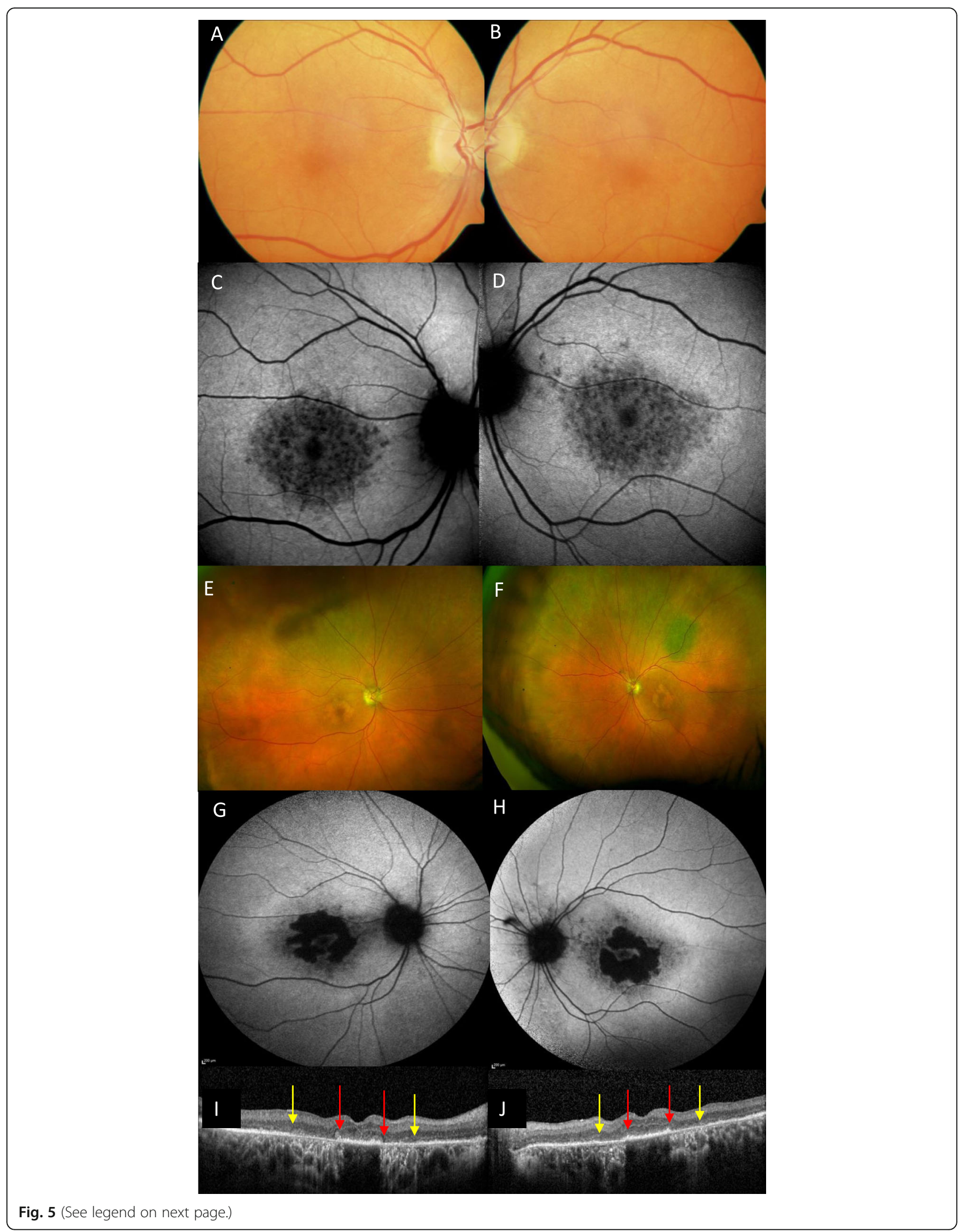


(See figure on previous page.)

Fig. 5 Imaging of proband's father (I/2) Images (a to d) at age 73 (asymptomatic. Colour images of both maculae which appeared normal (a and b). Autofluorescence (AF) revealed central patchy reduction in AF signal, consistent with early atrophy (c and d). Images E to J of I:2 9 years later. Optos imaging showing distinct macular atrophy in both eyes and a choroidal naevus at left superotemporal arcade (e and $\mathbf{f}$ ). AF imaging showing further atrophy at the central macula with central foveal sparing (g and $\mathbf{h})$. Optical coherence tomography (OCT) showing preservation of the ellipsoid zone in the foveal area demarcated by red arrows, and the extent of loss of the ellipsoid zone denoted by yellow arrows (i and $\mathbf{j}$ )

their cohort was similar to the VA seen in our 3 patients [10]. Three studies report an electronegative ERG with some $C R X$ mutations $[6,10,11]$. Cone dystrophy alone, as seen in the proband in this family has been previously described [12] and Hull et al. describe a rod cone dystrophy phenotype associated with this same CRX c.121C > T variant [11].

Intra and inter-familial variability of expression and reduced penetrance seem to be a hallmark of CRX [1015]. Romdhane et al. report intra-familial variability and reduced penetrance, as seen in this family and a BEM phenotype [15]. BEM associated with $C R X$ sequence variants has been reported by a number of authors, characterised by a central decreased AF signal surrounded by a ring of increased $\mathrm{AF}$ and loss of the $\mathrm{EZ}$ on OCT imaging and foveal preservation $[11,16]$. It is clear however that the presence of BEM is not pathognomic for $C R X$, as $B E M$ has been described in association with sequence variants in $C R X, A B C A 4$ and $G U C Y 2 D$ [16]. The spared fovea has been seen in patients with $C R X$ mutations before, with Boulanger-Scemama et al. reporting that half of their cohort of $C R X$ patients had a spared fovea [17].

$C R X$ variants have been described in association with Leber congenital amaurosis and rod cone dystrophy, in addition to the typical cone rod/macular dystrophy phenotype [11].

More recently subsequent to the testing identifying the $C R X$ variant in this case, Wollock et al. reported on the use of genome wide enrichment analysis of qualifying variants for dominant inheritance pattern diseases using the collapsed analysis approach. This type of approach reached a study wide significance for identification of $C R X$ mutations in patients that were clinically diagnosed with STGD1, CRD, BEM, PD and MD, but were not found to have mutations in the $A B C A 4$ gene thus highlighting the importance of using a multiple gene panel when assessing these patients [18].

In summary this family study illustrates the complexity of genetic testing in the context of phenocopies, reduced penetrance and variable expressivity. This is illustrated by the discovery of a clinical phenotype in the asymptomatic father using multimodal imaging, revisiting the original diagnosis in the sister, and showing non segregation of the $A B C A 4$ variant, as well as identifying the pathogenic $C R X$ variant in all three affected family members using NGS. It highlights the importance of comprehensive genetic testing and a careful family survey. If a family survey had been performed at the initial visit, the asymptomatic father would have been identified as affected, and an autosomal dominant pattern of inheritance with segregation would have excluded $A B C A 4$ as a causative gene. However, it is not always possible to perform a family survey, which can make interpretation of genetic testing results difficult in cases where more than one variant is identified as potentially causative and where there are known phenocopies.

With the advent of whole genome analysis many potential pathogenic variants will be identified in different genes; accurate phenotyping and family studies will be key in identifying the variant(s) in causative genes, and will enable diagnosis in phenocopies and complex phenotype-genotype correlations. This case highlights the variable expression and reduced penetrance seen in $C R X$ associated retinal dystrophies. It also emphasises the value of access to NGS genetic analysis and the importance of family studies with segregation to complement and direct genetic testing.

\section{Abbreviations}

ABCA4: ATP binding cassette subfamily A member 4; AD: Autosomal dominant; AF: Autofluorescence; AR: Autosomal recessive; BEM: Bull's eye maculopathy; CRD: Cone-Rod dystrophy; CRX: Cone-rod homeobox; OCT: Optical coherence tomography; STGD1: Stargardt disease

\section{Acknowledgements}

We would like to thank the family, and Sophie Marlowe and Clare ArnisonNewgass, Research Coordinator and Ophthalmic Genetic Research Nurse respectively, for their help with this project.

\section{Authors' contributions}

AHN and SMD initially designed the concept of this work. KAZH, SB, SH, MES and PC analysed the patient data. SA-K, KAZH, SB, SH and SMD drafted the article. All authors read and approved the final manuscript.

\section{Funding}

We are grateful for funding from the Thames Valley Clinical Research Network, which enabled this study. The funder had no role in the design collection, analysis and interpretation of the data in this study or in the writing of the manuscript. SA-K is funded by the Qatar Foundation (GSRA6-10329-19010).

\section{Availability of data and materials}

All data generated or analysed during this study are included in this published article.

\section{Declarations}

Ethics approval and consent to participate

Ethics Committee approval was obtained from the Essex 2 Research Ethics Committee (reference 08/H0302/96) with written patient consent, and this study was conducted in adherence to the tenets of the Declaration of Helsinki. 


\section{Consent for publication}

Written informed consent was obtained from the patients for this case report and any accompanying images.

\section{Competing interests}

The authors declare that they have no competing interests.

\section{Author details}

${ }^{1}$ Nuffield Laboratory of Ophthalmology, Nuffield Department of Clinical Neurosciences, University of Oxford, Oxford, UK. ${ }^{2}$ Oxford Eye Hospital, John Radcliffe Hospital, Headley Way, Oxford OX9 3DU, UK. ${ }^{3}$ Oxford Medical Genetics Laboratory, Oxford University Hospitals NHS Foundation Trust, Oxford, UK. ${ }^{4}$ Oxford Centre for Genomic Medicine, Oxford University Hospitals NHS Foundation Trust, Oxford, UK.

Received: 24 June 2019 Accepted: 23 March 2021

Published online: 09 April 2021

\section{References}

1. Allikmets R, Shroyer NF, Singh N, Seddon JM, Lewis RA, Bernstein PS, et al. Mutation of the Stargardt disease gene (ABCR) in age-related macular degeneration. Science. 1997;277(5333):1805-7

2. Downes SM, Packham E, Cranston T, Clouston P, Seller A, Nemeth AH. Detection rate of pathogenic mutations in ABCA4 using direct sequencing: clinical and research implications. Arch Ophthalmol (Chicago, III: 1960). 2012;130(11):1486-90.

3. Zaneveld J, Siddiqui S, Li H, Wang X, Wang H, Wang K, et al. Comprehensive analysis of patients with Stargardt macular dystrophy reveals new genotype-phenotype correlations and unexpected diagnostic revisions. Genet Med. 2015;17(4):262-70.

4. Zernant J, Schubert C, Im KM, Burke T, Brown CM, Fishman GA, et al. Analysis of the ABCA4 gene by next-generation sequencing. Invest Ophthalmol Vis Sci. 2011;52(11):8479-87.

5. Shanks ME, Downes SM, Copley RR, Lise S, Broxholme J, Hudspith KA, et al, Next-generation sequencing (NGS) as a diagnostic tool for retinal degeneration reveals a much higher detection rate in early-onset disease. Eur J Hum Genet. 2013;21(3):274-80.

6. Swain PK, Chen S, Wang QL, Affatigato LM, Coats CL, Brady KD, et al. Mutations in the cone-rod homeobox gene are associated with the conerod dystrophy photoreceptor degeneration. Neuron. 1997;19(6):1329-36.

7. Michaelides $M$, Chen LL, Brantley MA Jr, Andorf JL, Isaak EM, Jenkins SA et al. ABCA4 mutations and discordant ABCA4 alleles in patients and siblings with bull's-eye maculopathy. Br J Ophthalmol. 2007;91(12):1650-5.

8. Chen S, Wang QL, Nie Z, Sun H, Lennon G, Copeland NG, et al. Crx, a novel Otx-like paired-homeodomain protein, binds to and transactivates photoreceptor cell-specific genes. Neuron. 1997;19(5):1017-30.

9. Freund $\mathrm{CL}$, Gregory-Evans CY, Furukawa T, Papaioannou M, Looser J, Ploder $L$, et al. Cone-rod dystrophy due to mutations in a novel photoreceptorspecific homeobox gene (CRX) essential for maintenance of the photoreceptor. Cell. 1997;91(4):543-53.

10. Nishiguchi KM, Kunikata H, Fujita K, Hashimoto K, Koyanagi Y, Akiyama M, et al. Association of CRX genotypes and retinal phenotypes confounded by variable expressivity and electronegative electroretinogram. Clin Exp Ophthalmol. 2020;48(5):644.

11. Hull S, Arno G, Plagnol V, Chamney S, Russell-Eggitt I, Thompson D, et al. The phenotypic variability of retinal dystrophies associated with mutations in CRX, with report of a novel macular dystrophy phenotype. Invest Ophthalmol Vis Sci. 2014;55(10):6934-44.

12. Kitiratschky VB, Nagy D, Zabel T, Zrenner E, Wissinger B, Kohl S, et al. Cone and cone-rod dystrophy segregating in the same pedigree due to the same novel CRX gene mutation. Br J Ophthalmol. 2008;92(8):1086-91.

13. Sohocki MM, Sullivan LS, Mintz-Hittner HA, Birch D, Heckenlively JR, Freund CL, et al. A range of clinical phenotypes associated with mutations in CRX, a photoreceptor transcription-factor gene. Am J Hum Genet. 1998;63(5):1307-15.

14. Chapi M, Sabbaghi H, Suri F, Alehabib E, Rahimi-Aliabadi S, Jamali F, et al. Incomplete penetrance of CRX gene for autosomal dominant form of conerod dystrophy. Ophthalmic Genet. 2019;40(3):259-66.

15. Romdhane K, Vaclavik V, Schorderet DF, Munier FL, Viet TH. CRX-linked macular dystrophy with intrafamilial variable expressivity. Ophthalmic Genet. 2018;39(5):637-41.
16. Nasser F, Kurtenbach A, Kohl S, Obermaier C, Stingl K, Zrenner E. Retinal dystrophies with bull's-eye maculopathy along with negative ERGs. Doc Ophthalmol. 2019;139(1):45-57.

17. Boulanger-Scemama E, Mohand-Said S, El Shamieh S, Demontant V, Condroyer C, Antonio A, et al. Phenotype analysis of retinal dystrophies in light of the underlying genetic defects: application to cone and cone-rod dystrophies. Int J Mol Sci. 2019;20:19.

18. Wolock CJ, Stong N, Ma CJ, Nagasaki T, Lee W, Tsang SH, et al. A casecontrol collapsing analysis identifies retinal dystrophy genes associated with ophthalmic disease in patients with no pathogenic ABCA4 variants. Genet Med. 2019;21(10):2336-44.

\section{Publisher's Note}

Springer Nature remains neutral with regard to jurisdictional claims in published maps and institutional affiliations.
Ready to submit your research? Choose BMC and benefit from:

- fast, convenient online submission

- thorough peer review by experienced researchers in your field

- rapid publication on acceptance

- support for research data, including large and complex data types

- gold Open Access which fosters wider collaboration and increased citations

- maximum visibility for your research: over $100 \mathrm{M}$ website views per year

At BMC, research is always in progress.

Learn more biomedcentral.com/submissions 